\title{
FACTOR ANALYSIS OF THE CO2 EMISSIONS IN THE UNITED STATES WITH IMPLICATIONS FOR THE ENVIRONMENTAL POLICY
}

\author{
Olen Dias, Alexander Vaninsky \\ Mathematics Department, Hostos Community College of The City University of New York \\ 500 Grand Concourse, Bronx, NY 10451 USA \\ odias@hostos.cuny.edu \\ Mathematics Department, Hostos Community College of The City University of New York \\ 500 Grand Concourse, Bronx, NY 10451 USA \\ avaninsky@hostos.cuny.edu
}

\begin{abstract}
This paper applies the Generalized Divisia Index to decompose the CO2 emissions into eight components and uses the Factor Analysis to determine their clusters - the combinations of related components that play the leading role. Economic analysis of these clusters allows for the determination of the main drivers of the $\mathrm{CO} 2$ emissions. As a case study, we used the data of the United States from 1950 through 2040 separated into three periods: 1950 - 1980; 1981 - 2012, and 2013 - 2040, each characterized by a specific type of socioeconomic development: industrial, post-industrial, and information, respectively. Data for the last period are projections. As a result, we got an insight into the typology of the $\mathrm{CO} 2$ emissions and obtained recommendations on environmental policy aimed at their mitigation
\end{abstract}

\section{Indexing terms/Keywords}

CO2 emissions, Environmental policy, Generalized Divisia Index, Kaya identity, Factor analysis, Cluster analysis, Typology.

\section{Academic Discipline And Sub-Disciplines}

Statistics; Economic Modeling; Environmental Studies; Ecological Economics; Environmental Policy;

\section{SUBJECT CLASSIFICATION}

Library of Congress Classification HA29-32 Theory and method of social science statistics

\section{TYPE (METHOD/APPROACH)}

Quasi-Experimental

\section{Council for Innovative Research}

Peer Review Research Publishing System

Journal: Journal of Social Sciences Research

Vol .7, No.3

jssreditor.cir@gmail.com

www.jssronline.com 


\section{INTRODUCTION}

As the report of the Intergovernmental Panel on Climate Change, ICCP (2014), states, human intervention aimed to reduce the sources of greenhouse gases $(\mathrm{GHG})$ is strongly needed to prevent global warming and climate change. As this report also mentions, the opportunities for the mitigation of the $\mathrm{CO} 2$ emissions are limited due to the existence of economic, societal, and cultural differences among countries. The GHG mitigation policy should be consistent with sustainable development, equity, value judgements and ethical considerations. Also, all individual agents should be prepared to forego some of their own interests. Finally, the climate policy is subject to the ability of individuals, organizations, and countries to perceive related risks and uncertainties.

Fossil fuel combustion and industrial processes contribute about $78 \%$ of the total. Between 2000 and 2010 , the increase in anthropogenic GHG emissions resulted from energy supply (47\%), industry (30\%), transport $(11 \%)$ and buildings (3\%) sectors. Among the most important drivers of the increase in GHG emissions were economic development and population growth. Without the relevant mitigation policies, this trend may begin threatening the human wellbeing and even existence.

The instruments available for the policymakers are different in the societies located at different stages of economic development because the differences in the main sources of economic growth. In this paper, we distinguish among the three main types of the societies: industrial, post-industrial, and information. In the industrial society, the most of the gross domestic product is generated in the industrial sectors of the economy. When collection of the service sectors takes the lead, the society is referred to as post-industrial, Bell (1973). Finally, when creation, use, and manipulation of information becomes the main factor of international competitive advantage, the society reaches the information stage, Beniger (1986). This paper covers the period of 1950 through 2040 during whichn the United States passed the first two stages and is expected to enter the third, the highest, stage of the information society. We demonstrate how the CO2 factor structure changes depending on the level of economic development. The investigation of this change is important in view of the practical significance of the mitigation of the $\mathrm{CO} 2$ emissions. The main objective is to help determine the driving forces behind the $\mathrm{CO} 2$ emissions and suggest the ways of change in the environmental policies that are relevant to the level of economic growth.

The tools of investigation used in this paper are the Generalized Divisia Index Method (GDIM), Vaninsky (2014), and Factor Analysis, Thompson (2004). The paper is organized as follows. Section 2 presents the mathematical model, Section 3 the results and their discussion, and Section 4 provides conclusive remarks and outlines possible next steps.

\section{MATHEMATICAL MODEL}

In this section, we follow Vaninsky (2014) in the description of the mathematical means used in this paper. The basic tool is the factorial decomposition of the CO2 emissions of factors as suggested by Kaya identity, Kaya (1990), extended to include the interconnected factors, Vaninsky $(1983,2014)$. Methodologically, the Kaya identity may be traced to the seminal publications of Laspeyres (1871), and Paasche (1874). These publications suggested the additive decomposition of the resultant indicator $\mathrm{Z}$ given in the multiplicative form

as

$$
Z=X_{1} \cdot X 2 \cdot \ldots \cdot X_{n}
$$

$$
\Delta Z=\Delta Z[X 1]+\Delta Z[X 2]+\ldots+\Delta Z[X n],
$$

where $\Delta Z$ and $\Delta Z[X i]$ stand for the change in $Z$ and its parts corresponding to the factorial indicators $X$, respectively. The idea was to change the factorial indicators $X i$ one at a time and to assign at each step the partial change in the level of $Z$ to a factor $X_{i}$, respectively. One of the disadvantages of this approach is the necessity of a priori ordering of the indicators $X_{i}$. This weakness was overcome in the publication of Divisia (1925) that suggested the statement of the problem in continuous time. This publication assumed that the factorial indicators change continuously in time as $X_{i}=X_{i}(t)$, so that the necessity to put the factorial indicators in order was eliminated. The continuous-time factorial decomposition is as follows :

$$
\Delta Z=\Sigma \Delta Z\left[X_{i}\right]=\Sigma \int X_{1} \cdot X_{2} \cdot \ldots \cdot X_{i-1} \cdot X_{i}^{\prime} X_{i+1} \ldots \cdot X_{n} \cdot d t,
$$

where $\Sigma$ is the summation symbol, symbol $\int$ stands for the integration, $X_{i}^{\prime}$ is the derivative of $X_{i}$ by time $t$, and integration is done by time $t$ as well. With this approach, the impact of a factor $X_{i}$ on the change in the resultant indicator $Z$ is as follows:

$$
\Delta Z\left[X_{i}\right]=\int X_{1} \cdot X_{2} \cdot \ldots \cdot X i-1 \cdot X i^{\prime} \cdot X_{i+1} \ldots \cdot X_{n} \cdot d t, i=1 . . n .
$$

This approach was further extended in Scheremet et al. (1971) to include any continuously differentiated functions, rather than products of the factorial indicators only. Assuming

$$
Z=f(X)=f\left(X_{1}, \ldots, X_{n}\right),
$$

the authors received the factorial decomposition as:

$$
\Delta Z=Z_{1}-Z_{0}=\int_{L} d Z=\int_{L} f_{1}^{\prime} d X_{1}+\int_{L} f_{2}^{\prime} d X_{2}+\ldots+\int_{L} f_{n}^{\prime} d X_{n}
$$

where 


$$
\Delta Z\left[X_{i}\right]=\int_{L}^{\prime} f_{j}^{\prime} d X_{i}=\int_{t_{0}}^{t_{1}} f_{i}^{\prime} X_{i}^{\prime} d t,
$$

$f_{i}^{\prime}$ is a partial derivative with respect to the $i$-th argument, and $X_{i}^{\prime}=d X / d t$. Formula (6) may be rewritten in the vector form as

$$
\Delta Z=\int_{L} \nabla Z^{T} \cdot d X
$$

where $\Delta Z$ is a row decomposition-vector with components $\Delta Z\left[X_{i}\right]$,

$$
\nabla \boldsymbol{Z}=\left\langle f_{1}^{\prime}, \ldots, f_{n}^{\prime}>^{\mathrm{T}}\right.
$$

is a column gradient vector of the function $f\left(X_{1}, \ldots, X_{n}\right)$, upper index $T$ stands for the transposition, the dot-symbol stands for the dot-product of two vectors, and $d X$ is a diagonal matrix with elements $d X_{1}, d X_{2}, \ldots, d X_{n}$.

Publications of Meerovoch (1974) and Vaninsky and Meerovich (1978) introduced a new class of the decomposition problems related to the structural change; see Maital and Vaninsky (2000) for details. The division - Sheremet approach was extended further in publications Vaninsky $(1983,1986)$ by the introduction of the factorial indicators that are not included in the model directly. This approach was applied in Vaninsky (2014) to the decomposition of the CO2 emissions. We will refer to it in this paper below as a Generalized Divisia Index Method (GDIM).

In the framework of the GDIM, the resultant indicator $Z$ is a function of the factorial indicators $X_{1}, X_{2}, \ldots, X_{n}$ that are interconnected by a system of equations:

$$
\begin{gathered}
Z=f(X)=f\left(X_{1}, \ldots, X n\right), \\
\Phi_{j}\left(X_{1}, \ldots X_{n}\right)=0, j=1, \ldots, k
\end{gathered} .
$$

The second equation may be written in matrix form as

$$
\Phi \frown X \cong 0 \text {. }
$$

The following formula was proved in Vaninsky (1984):

$$
\Delta Z[X \mid \Phi]=\int_{L} \nabla Z^{\top}\left(I-\Phi_{X} \Phi_{X}^{+}\right) d X
$$

where coordinates of the row vector $\Delta Z[X / \Phi]$ are the components of the factorial decomposition of the change in the resultiant indicator $Z$, and $\Phi_{X}$ is a Jacobian matrix for the matrix-valued function $\Phi(X)$ :

$$
\left(\Phi_{X}\right)_{i j}=\frac{\partial \Phi_{j}}{\partial X_{i}},
$$

upper index "+" denotes the generalized inverse matrix, and $I$ is the identity matrix. It is known that if the columns of the matrix $\boldsymbol{\Phi}_{x}$ are linearly independent, then

$$
\boldsymbol{\Phi}_{x}^{+}=\left(\boldsymbol{\Phi}_{x}{ }^{T} \boldsymbol{\Phi}_{x}\right)^{-1} \boldsymbol{\Phi}_{x}{ }^{T}
$$

See Albert (1972) for details. It should be mentioned that since the formula (12) uses an operator of projection on a surface, the factors should be measured in relative units; see Vaninsky $(1984,1987)$ for detail.

Vaninsky's publications $(2013,2014)$ applied this approach to decomposition of the CO2 emissions by factors of GDP, energy, population, their carbonization intensities, and other factors by extending the Kaya identity, Kaya (1990). This identity is a particular case of index model (1) adapted to environmental studies. It expresses the CO2 emissions as a product of carbon intensity of energy $(C O 2 / E)$, the energy intensity of economic activity (E/GDP), GDP per capita (GDP/P), and population $(P)$ :

$$
C O 2=(C O 2 / E) \times(E / G D P) \times(G D P / P) \times P .
$$

The impact of each of the factors can be computed by using either the discrete Laspeyres-Paasche approach or the continuous-time approach of Divisia. The Kaya identity is a useful practical tool for finding the ways of reducing the $\mathrm{CO} 2$ emissions. For example, the Kaya-identity-based decomposition is available as a part of statistical data published by the U.S. Energy Information Administration on its website www.eia.gov. This approach, however, may be critiqued from two viewpoints. Firstly, only the population indicator is included as a quantitative indicator; neither energy nor GDP is considered within the framework of the factorial model (15). Secondly, different factor models similar to (15) may be offered that lead to different factorial decompositions.

Keeping this in mind, we follow in this paper publication of Vaninsky (2014) and transform the Kaya identity into factor model (10), which allows for the expansion of the analytical base of Kaya identity by the inclusion of different quantities 
and relative indicators. To do that, we begin with an observation that $\mathrm{CO} 2$ emissions may be presented in one of the three ways:

$$
\text { CO2 }=(C O 2 / G D P) \cdot G D P=(C O 2 / \text { Energy }) \cdot \text { Energy }=(C O 2 / \text { Population }) \cdot \text { Population }
$$

Our objective is to incorporate all of them symmetrically into the factorial analysis. For the sake of readability, we use the following denominations: $Z=C O 2, X_{1}=G D P, X_{3}=$ Energy consumption, $X_{5}=$ Population; $X_{2}, X_{4}$, and $X_{6}$ are the carbon intensities: $X_{2}=(C O 2 / G D P), X_{4}=(C O 2 / E n e r g y), X_{6}=(C O 2 /$ Population), correspondingly. Following Vaninsky(2014), we included two more relative indicators in the model to increase its explanatory power: $X_{7}=\left(\right.$ GDP/Population), and $X_{8}=$ (Energy/GDP).

In terms of the newly defined variables, formula (16) becomes

$$
Z=X_{1} X_{2}=X_{3} X_{4}=X_{5} X_{6}
$$

To apply the GDIM, we separate these equations into a factor model and equations of the factors' interconnections as follows:

$$
\begin{aligned}
& Z=X_{1} X_{2}, \\
& X_{1} X_{2}=X_{3} X_{4}, \quad X_{1} X_{2}=X_{5} X_{6}, X_{7}=X_{1} / X_{5}, X_{8}=X_{3} / X_{1}
\end{aligned}
$$

and rewrite the equations (18) in the form (10):

$$
\begin{aligned}
& Z=X_{1} X_{2}, \\
& X_{1} X_{2}-X_{3} X_{4}=0, \\
& X_{1} X_{2}-X_{5} X_{6}=0, \\
& X_{1}-X_{5} X_{7}=0, \\
& X_{3}-X_{1} X_{8}=0
\end{aligned}
$$

As shown in Vaninsky (2014), a gradient of the function $Z(X)$ and the Jacobian matrix $\boldsymbol{\Phi}_{X}$ are as follows:

$$
\begin{aligned}
\nabla \boldsymbol{Z} & =\left\langle X_{2}, X_{1}, 0,0,0,0,00\right\rangle^{\mathrm{T}}, \\
\boldsymbol{\Phi}_{X}= & \left(\begin{array}{cccccccc}
x_{2} & x_{1}-x_{4} & -x_{3} & 0 & 0 & 0 & 0 \\
x_{2} & x_{1} & 0 & 0 & -x_{6} & -x_{5} & 0 & 0 \\
1 & 0 & 0 & 0 & -x_{7} & 0 & -x_{5} & 0 \\
-x_{8} & 0 & 1 & 0 & 0 & 0 & 0 & -x_{1}
\end{array}\right)^{\mathrm{T}}
\end{aligned}
$$

In this paper below, the quantitative factors $X_{1}=\mathrm{GDP}, X_{3}=$ Energy consumption, and $X_{5}=$ Population are considered exponential functions of a model time $t, 0 \leq t \leq 1$. The range of the model time change does not affect the final result; see Vaninsky $(1983,1987)$ for details. By doing so, we get all of the remaining factorial indicators and the resultant indicator $Z$ as the functions of the model time $t$ as well in the form:

$$
Q(t)=\left(Q_{1} / Q_{0}\right)^{t}
$$

where $Q$ stands for a quantitative or relative indicator $X_{i}$, or resultant indicator $Z$, and 0 and 1 are the lower indexes corresponding to base and final values, respectively. The derivatives with respect to time $t$ are

$$
\frac{d Q}{d t}=\ln \left(\frac{Q_{1}}{Q_{O}}\right) Q
$$

Publication Vaninsky (2014) presents a computer program in R-language, R Development Core Team (2011), that performs calculations. As a result, we obtain the decomposition of the chain rate of change in $\mathrm{CO} 2$ emissions into 8 factors mentioned above.

Our objective is to study the structure of the factorial decomposition obtained at different stages of economic development. To do so, we apply a technique of factor analysis, see Thompson(2004) for details. Factor analysis aims to represent a set of $n$ variables as linear combinations of a smaller number of $k$ factors. The factors are assumed to be independent random variables with zero mean value and a unit standard deviation. The terms of the linear combinations are called factor loadings. Factor analysis uses the rotation of the factors to make the factor loadings clearly separated by the variables. This allows for the interpretation of the variables having largest i-factor loadings as belonging to one cluster, related to this factor.

In matrix notation, the factor analysis model is as follows:

$$
X=\Lambda F+U,
$$

where $\boldsymbol{X}$ is an $n^{\times} N$ matrix representing $N$ observations over $n$ variables, $\boldsymbol{F}$ is a $k^{\times} N$ matrix of $k$ factors, $\boldsymbol{\Lambda}$ is an $n^{\times k}$ matrix of factor loadings, and $\boldsymbol{U}$ is an $n^{\times} n$ uniqueness matrix. In this model, $k<n<N$, and a matrix product $\boldsymbol{\Lambda} \boldsymbol{F}$ is interpreted as the communality of the variables. Factor analysis is aimed to make the matrix $\boldsymbol{U}$ as small as possible. 
In this paper below, we use 8 factorial decomposition elements as variables that are observed during the time periods corresponding to different stages of economic development.

\section{RESULTS AND DISCUSSION}

In this section we use statistical data on the U.S. economy for the period of $1950-2040$ available at the website of the U.S. Energy Information Administration www.eia.gov to obtain a deeper insight in the structure of the CO2 emissions. The data include indicators of CO2 equivalent emissions, GDP, energy consumption, and population. The data beyond 2013 are projections. The data were divided into three sets: 1950 - 1980, $1981-2012$, and $2013-2040$, roughly corresponding to the three different stages of the U.S. economy: industrial, post-industrial, and information. We expect that the environmental policy, technology and the use of energy are quite different in these periods, and we aim to detect and clarify these differences.

Quantitative data for 1950 - 2040 are given in table 1. Figures 1 and trends with the slope of 0.548 percentage points per year. There are just two sub-periods when the rates of the $\mathrm{CO} 2$ emissions decreased. Both relate to the recession periods of the 1980's and 2008 - 2010. However, the dynamics of the rates of change in the CO2 emissions are quite different in these three periods. The average rates of increase in the CO2 emissions during the 1950 - 1980, 1981 - 2012 and 2013 - 2040 periods are 23.5, 4.0, and 2.3 mills, respectively. This means that the increase in the CO2 emissions in 1981 - 2012 is 5.9 times less, and in 2013 - 2040, is 1.7 times less with regard to the previous period. This observation is in line with our assumption that the type of economy - industrial, post-industrial, or information - is among the main factor of the $\mathrm{CO} 2$ emissions. The higher the level of the economy, the better technology is in use, the more attention is paid to the quality of life, and more possibilities become available to satisfy the advanced criteria of the $\mathrm{CO} 2$ mitigation.

We applied the Generalized Divisia Index method, Vaninsky (2014), to separate the rate of change in the CO2 emissions into 8 components. A program in R-language used for the computations is provided in that publication; the $\mathrm{R}$ language developed by the R Development Core Team (2011) is available for free download. The obtained results, separated by the periods of 1950-1980, 1981-2012, and 2013 - 2040, respectively, are shown in Table 2. Figure 3 presents average contributions of each component to the rate of change in the CO2 emissions. As follows from these data, the GDP remains the main factor of the increase in the $\mathrm{CO} 2$ emissions across the periods with decarbonization of GDP as the main factor of their decrease. The role of energy is essential in the first period only but its impact strongly decreases after that. Carbonization of the population is essential but reverses its effect from positive in the first period to negative in the two following ones.

To further investigate the structure of the $\mathrm{CO} 2$ rates of increase decomposition, we applied the technique of factor analysis, referring the reader to Thompson (2004) for details, implemented in R language version 3.3.1. We used the library PSYCH of the package MASS. We began with the determination of the number of factors by using the procedure VSS with rotation parameter varimax. For all three time periods, the number of factors varied from two to four depending on the criteria embedded in the procedure. For the factor analysis and finding the clusters among the decomposition variables, we applied the procedure ICLUST with up to four factors. The results are shown in table 3 and figure 4.

As follows from the obtained results, the first two clusters include, depending on the periods, the quantitative indicators of Energy consumption and GDP (industrial, 1950-1980), Energy consumption (post-industrial, 1981 - 2012), and GDP (information, 2013 -2040). This means that at the industrial stage, both GDP and energy are the CO2 drivers since the production processes are energy intensive. In the post-industrial stage, when a greater part of the GDP is produced by using low-energy technology, only the total amount of energy matters. As a result, the role of the GDP as a CO2 driver decreases and it moves to the less significant cluster 2 . As the society moves to the information era, all sources of energy become less CO2- emitting, and, thus, only the scale of the economy becomes the primary quantitative factor. This leads to the increase in the rank of the GDP while the energy indicator moves to the cluster 3.

Observations over the relative indicators reveal that the carbonization of the population (the CO2 over population) keeps its important role in all three types of economies. It is in the cluster 1 in the industrial and information economies and in cluster 2 in the post-industrial economy. At the same time, there is a difference between the industrial and more advanced economies. In the industrial and information economies, a factor of economic development - GDP per capita - plays a role as a part of the cluster 2 while at the post-industrial stage it changes for the energy intensity of the GDP, the factor of industrial technology. It also may be mentioned that carbonization of the GDP factor is important at both advanced stages of economic development. It is a part of the cluster 1 in both post-industrial and information economies.

The mentioned changes in the clusters' compositions are suggested to play a role in the formulation of environmental policy aimed at mitigation of the $\mathrm{CO} 2$ emissions and finding the ways of its implementation via economic restructuring.

\section{CONCLUSIONS}

In this paper we analyzed the CO2 emissions for the periods of 1950-1980, 1980-2012, and 2013-2040, with data beyond 2013 being projections made by the U.S. Energy Information Administration. These periods roughly correspond to the

Table 1. Quantitative indicators ${ }^{a}$

\begin{tabular}{|c|c|c|c|c|c|c|c|c|c|}
\hline Year & $\mathrm{CO2}^{\mathrm{b}}$ & GDP $^{\mathbf{b}}$ & Energy $^{b}$ & $\begin{array}{l}\text { Popul } \\
\text { ation b }\end{array}$ & Year & $\mathrm{CO}^{\mathrm{b}}$ & GDP $^{b}$ & Energy $^{b}$ & $\begin{array}{l}\text { Popul } \\
\text { ation }^{\text {b }}\end{array}$ \\
\hline (1) & (2) & (3) & (4) & (5) & (1) & (2) & (3) & (4) & $(5)$ \\
\hline
\end{tabular}




\begin{tabular}{|c|c|c|c|c|c|c|c|c|c|}
\hline 1951 & 2671 & 2159 & 36974 & 155 & 1997 & 5584 & 9846 & 94602 & 273 \\
\hline 1952 & 2611 & 2242 & 36748 & 158 & 1998 & 5636 & 10275 & 95018 & 276 \\
\hline 1953 & 2670 & 2345 & 37664 & 160 & 1999 & 5688 & 10771 & 96652 & 279 \\
\hline 1954 & 2553 & 2330 & 36639 & 163 & 2000 & 5868 & 11216 & 98815 & 282 \\
\hline 1955 & 2819 & 2498 & 40208 & 166 & 2001 & 5761 & 11338 & 96168 & 285 \\
\hline 1956 & 2910 & 2548 & 41754 & 169 & 2002 & 5804 & 11543 & 97645 & 288 \\
\hline 1957 & 2882 & 2599 & 41787 & 172 & 2003 & 5855 & 11836 & 97978 & 290 \\
\hline 1958 & 2827 & 2575 & 41645 & 175 & 2004 & 5975 & 12247 & 100162 & 293 \\
\hline 1959 & 2934 & 2760 & 43466 & 178 & 2005 & 5999 & 12623 & 100282 & 296 \\
\hline 1960 & 3038 & 2829 & 45086 & 181 & 2006 & 5920 & 12959 & 99630 & 298 \\
\hline 1961 & 3064 & 2894 & 45738 & 184 & 2007 & 6024 & 13206 & 101296 & 301 \\
\hline 1962 & 3187 & 3070 & 47826 & 187 & 2008 & 5841 & 13162 & 99275 & 304 \\
\hline 1963 & 3309 & 3204 & 49644 & 189 & 2009 & 5424 & 12758 & 94559 & 307 \\
\hline 1964 & 3442 & 3389 & 51815 & 192 & 2010 & 5623 & 13063 & 97722 & 309 \\
\hline 1965 & 3587 & 3607 & 54015 & 194 & 2011 & 5498 & 13299 & 97301 & 312 \\
\hline 1966 & 3782 & 3842 & 57014 & 197 & 2012 & 5361 & 13580 & 96065 & 315 \\
\hline 1967 & 3875 & 3939 & 58905 & 199 & 2013 & 5421 & 13843 & 96494 & 317 \\
\hline 1968 & 4098 & 4130 & 62415 & 201 & 2014 & 5426 & 14232 & 96644 & 320 \\
\hline 1969 & 4270 & 4258 & 65614 & 203 & 2015 & 5418 & 14693 & 97729 & 322 \\
\hline 1970 & 4395 & 4266 & 67838 & 205 & 2016 & 5382 & 15154 & 98473 & 324 \\
\hline 1971 & 4446 & 4410 & 69283 & 208 & 2017 & 5418 & 15589 & 99341 & 327 \\
\hline 1972 & 4673 & 4644 & 72688 & 210 & 2018 & 5452 & 15987 & 99975 & 329 \\
\hline 1973 & 4876 & 4913 & 75684 & 212 & 2019 & 5469 & 16378 & 100428 & 332 \\
\hline 1974 & 4718 & 4886 & 73962 & 214 & 2020 & 5476 & 16753 & 100731 & 335 \\
\hline 1975 & 4578 & 4875 & 71965 & 216 & 2021 & 5487 & 17113 & 101126 & 337 \\
\hline 1976 & 4866 & 5137 & 75975 & 218 & 2022 & 5498 & 17487 & 101483 & 340 \\
\hline 1977 & 5018 & 5373 & 77961 & 220 & 2023 & 5506 & 17885 & 101860 & 342 \\
\hline 1978 & 5087 & 5673 & 79950 & 223 & 2024 & 5519 & 18316 & 102167 & 345 \\
\hline 1979 & 5166 & 5850 & 80859 & 225 & 2025 & 5526 & 18769 & 102453 & 347 \\
\hline 1980 & 5002 & 5834 & 78067 & 227 & 2026 & 5527 & 19232 & 102638 & 349 \\
\hline 1981 & 4646 & 5982 & 76106 & 230 & 2027 & 5531 & 19690 & 102858 & 352 \\
\hline 1982 & 4405 & 5866 & 73099 & 232 & 2028 & 5531 & 20154 & 103047 & 354 \\
\hline 1983 & 4377 & 6131 & 72971 & 234 & 2029 & 5528 & 20637 & 103141 & 357 \\
\hline 1984 & 4614 & 6572 & 76632 & 236 & 2030 & 5527 & 21139 & 103267 & 359 \\
\hline 1985 & 4600 & 6843 & 76392 & 238 & 2031 & 5524 & 21639 & 103373 & 361 \\
\hline 1986 & 4608 & 7081 & 76647 & 240 & 2032 & 5524 & 22139 & 103497 & 364 \\
\hline 1987 & 4766 & 7307 & 79055 & 242 & 2033 & 5530 & 22659 & 103706 & 366 \\
\hline 1988 & 4984 & 7607 & 82709 & 245 & 2034 & 5538 & 23200 & 103996 & 368 \\
\hline 1989 & 5070 & 7879 & 84786 & 247 & 2035 & 5546 & 23751 & 104284 & 370 \\
\hline 1990 & 5039 & 8027 & 84485 & 250 & 2036 & 5554 & 24315 & 104603 & 372 \\
\hline 1991 & 4993 & 8008 & 84438 & 253 & 2037 & 5564 & 24888 & 105023 & 374 \\
\hline 1992 & 5087 & 8280 & 85783 & 257 & 2038 & 5580 & 25477 & 105518 & 377 \\
\hline 1993 & 5189 & 8516 & 87424 & 260 & 2039 & 5591 & 26063 & 105934 & 379 \\
\hline 1994 & 5262 & 8863 & 89091 & 263 & 2040 & 5599 & 26670 & 106312 & 381 \\
\hline 1995 & 5323 & 9086 & 91029 & 266 & & & & & \\
\hline
\end{tabular}




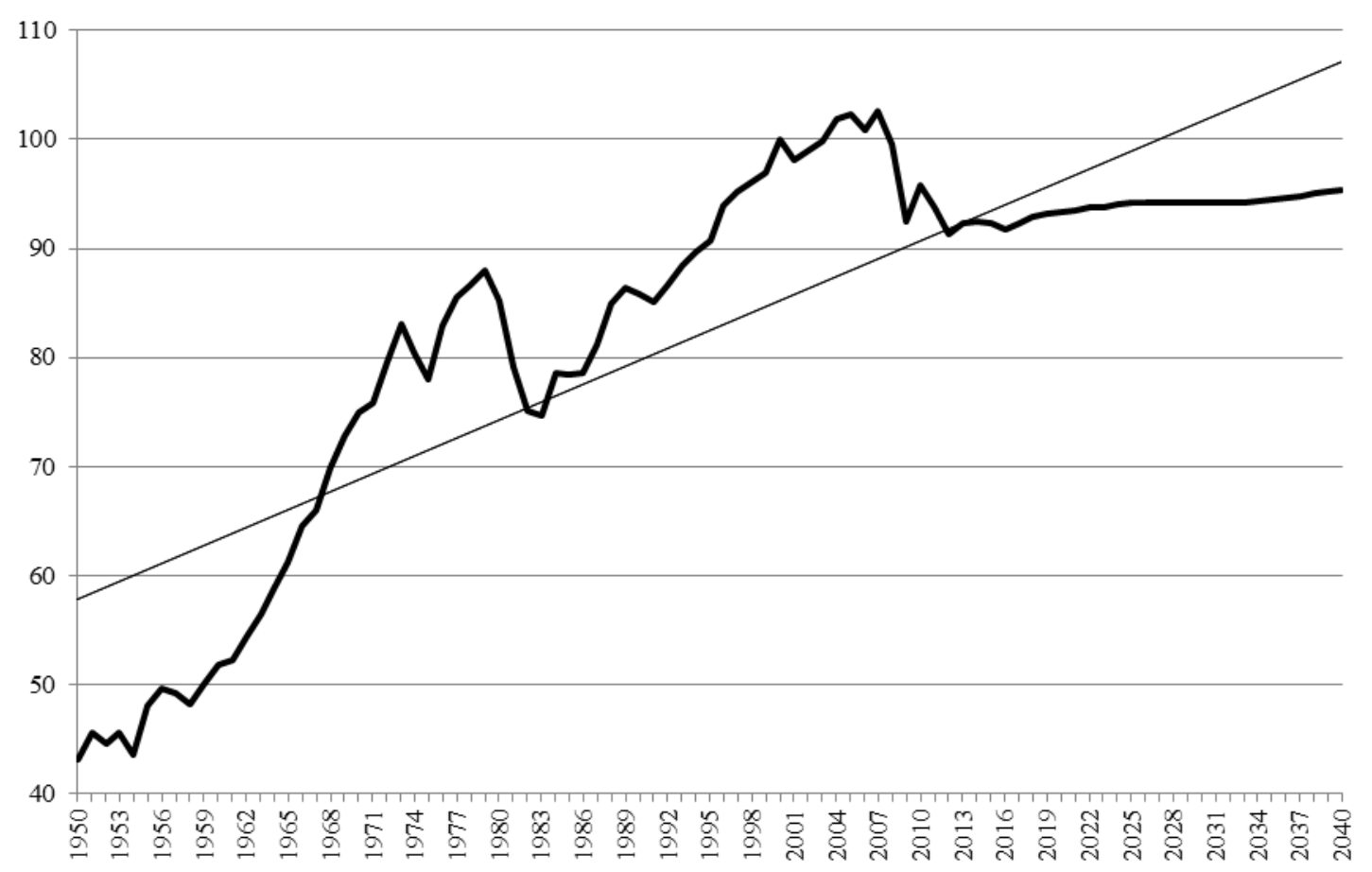

Fig. 1: $C O 2$ rate, $2000=100 \%$

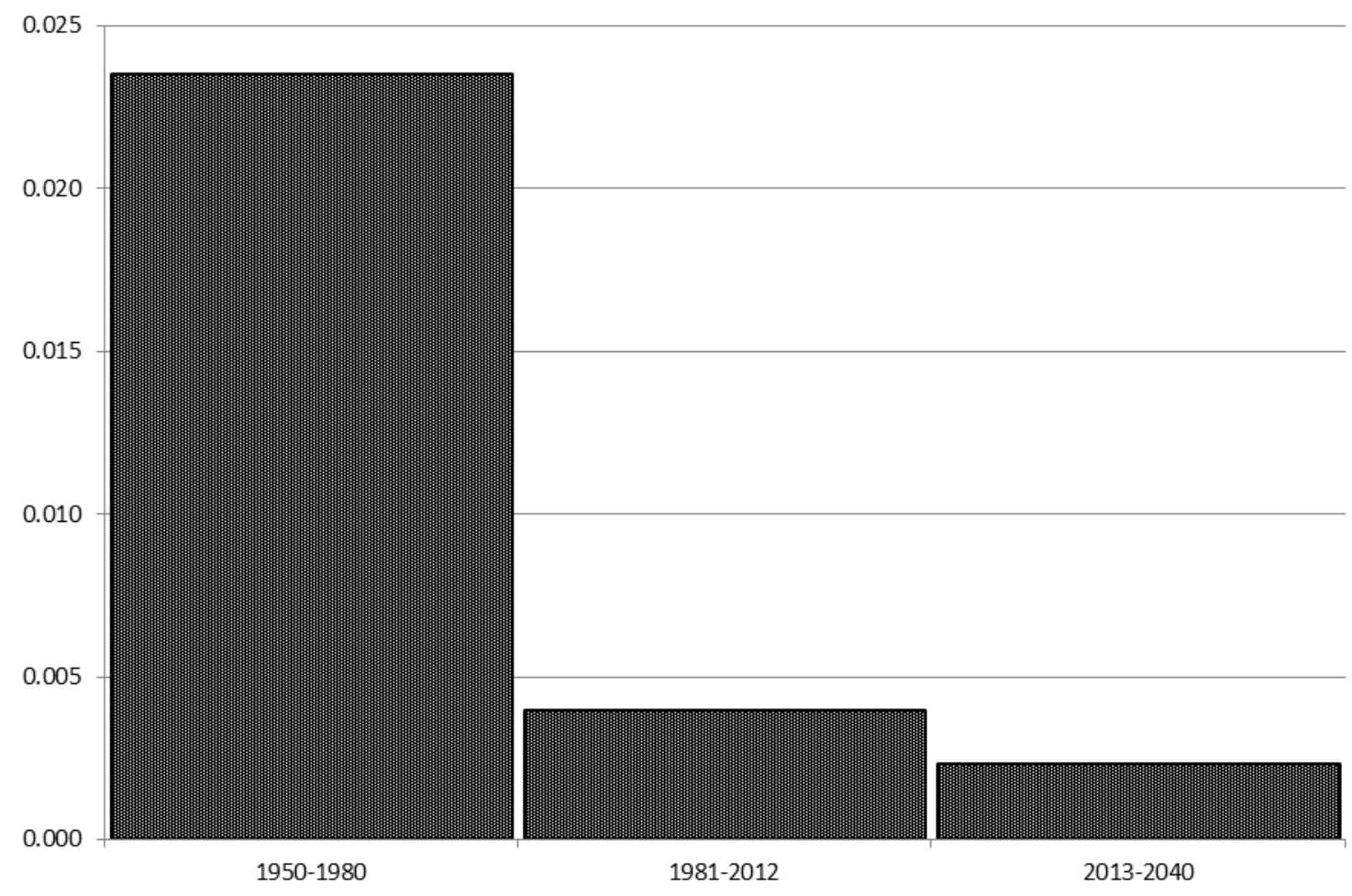

Fig. 2: Average rate of change in $\mathrm{CO} 2$ emissions 
Table 2. Contributions to the rate of change in $\mathrm{CO} 2$

\begin{tabular}{|c|c|c|c|c|c|c|c|c|c|}
\hline Year & GDP & Energy & $\begin{array}{l}\text { Popul } \\
\text { ation }\end{array}$ & $\begin{array}{l}\mathrm{CO} 2 / \\
\text { GDP }\end{array}$ & $\begin{array}{l}\mathrm{CO} 2 / \\
\text { Energy }\end{array}$ & $\begin{array}{l}\mathrm{CO} 2 / \\
\text { Popul } \\
\text { ation }\end{array}$ & $\begin{array}{l}\text { GDP/ } \\
\text { Popul } \\
\text { ation }\end{array}$ & $\begin{array}{l}\text { Energy/ } \\
\text { GDP }\end{array}$ & $\begin{array}{l}\mathrm{CO} 2 \text { chain } \\
\text { rate, Total }\end{array}$ \\
\hline$(1)$ & $(2)$ & (3) & (4) & \begin{tabular}{l|l} 
\\
\end{tabular} & (6) & (7) & (8) & \begin{tabular}{l|l}
$(9)$ \\
\end{tabular} & (10) \\
\hline 1951 & 0.0259 & -0.0067 & 0.0230 & -0.0043 & 0.0057 & 0.0131 & -0.0006 & 0.0000 & 0.0562 \\
\hline 1952 & 0.0125 & -0.0196 & -0.0027 & -0.0049 & 0.0057 & -0.0132 & 0.0000 & -0.0003 & -0.0225 \\
\hline 1953 & 0.0153 & -0.0076 & 0.0090 & -0.0015 & 0.0055 & 0.0020 & -0.0001 & 0.0000 & 0.0226 \\
\hline 1954 & -0.0021 & -0.0125 & -0.0096 & -0.0050 & 0.0057 & -0.0201 & -0.0001 & -0.0001 & -0.0438 \\
\hline 1955 & 0.0245 & 0.0103 & 0.0332 & 0.0018 & 0.0061 & 0.0290 & -0.0006 & -0.0002 & 0.1042 \\
\hline 1956 & 0.0066 & 0.0041 & 0.0133 & -0.0024 & 0.0061 & 0.0047 & 0.0000 & -0.0001 & 0.0323 \\
\hline 1957 & 0.0066 & -0.0098 & 0.0000 & -0.0032 & 0.0060 & -0.0092 & 0.0000 & -0.0001 & -0.0096 \\
\hline 1958 & -0.0030 & -0.0034 & -0.0016 & -0.00 & 0.0056 & -0.0118 & -0.0001 & 0.0000 & -0.0191 \\
\hline 1959 & 0.0239 & -0.0107 & 0.0151 & -0.00 & 0.0055 & 0.00 & -0.0005 & 0.0000 & 0.0379 \\
\hline 1960 & 0.0083 & 0.00 & 0.0123 & -0.00 & 0.0055 & 0.0063 & 0.0000 & 0.00 & 0.0355 \\
\hline 1961 & 0.0077 & -0.0048 & 0.0044 & -0.0016 & 0.0055 & -0.0027 & 0.0000 & 0.0000 & 0.0086 \\
\hline 1962 & 0.0202 & -0.0065 & 0.0153 & -0.0019 & 0.0051 & 0.0083 & -0.0003 & 0.0000 & 0.0401 \\
\hline 1963 & 0.0146 & -0.0018 & 0.0126 & 0.0002 & 0.0048 & 0.0079 & -0.0001 & 0.0000 & 0.0383 \\
\hline 1964 & 0.0193 & -0.0057 & 0.0147 & -0.0014 & 0.0048 & 0.0087 & -0.0003 & 0.0000 & 0.0402 \\
\hline 1965 & 0.0215 & -0.0070 & 0.0141 & -0.0001 & 0.0042 & 0.0099 & -0.0004 & 0.0000 & 0.0421 \\
\hline 1966 & 0.0219 & -0.0035 & 0.0185 & -0.0004 & 0.0040 & 0.0143 & -0.0005 & 0.0000 & 0.0544 \\
\hline 1967 & 0.0084 & -0.0002 & 0.0111 & -0.0029 & 0.0036 & 0.0046 & 0.0000 & 0.0000 & 0.0246 \\
\hline 1968 & 0.0163 & 0.0030 & 0.0199 & -0.0006 & 0.0034 & 0.0159 & -0.0003 & 0.0000 & 0.0576 \\
\hline 1969 & 0.0104 & 0.0036 & 0.0171 & -0.0030 & 0.0034 & 0.0107 & -0.0001 & -0.0001 & 0.0420 \\
\hline 1970 & 0.0006 & 0.0092 & 0.0112 & -0.0014 & 0.0040 & 0.0058 & 0.0000 & -0.0002 & 0.0293 \\
\hline 1971 & 0.0111 & -0.0072 & 0.0073 & -0.0035 & 0.0042 & -0.0004 & -0.0001 & 0.0000 & 0.0116 \\
\hline 1972 & 0.0179 & -0.0007 & 0.0164 & 0.0006 & 0.0036 & 0.0136 & -0.0003 & 0.0000 & 0.0511 \\
\hline 1973 & 0.0194 & -0.0046 & 0.0138 & 0.0007 & 0.0032 & 0.0114 & -0.0004 & 0.0000 & 0.0434 \\
\hline 1974 & -0.0018 & -0.0090 & -0.0074 & -0.0034 & 0.0031 & -0.0138 & 0.0000 & -0.0001 & -0.0324 \\
\hline 1975 & -0.0007 & -0.0092 & -0.0089 & -0.0009 & 0.0032 & -0.0130 & 0.0000 & -0.0001 & -0.0297 \\
\hline 1976 & 0.0181 & 0.0030 & 0.0186 & 0.0024 & 0.0031 & 0.0180 & -0.0003 & 0.0000 & 0.0629 \\
\hline 1977 & 0.0154 & -0.0048 & 0.0088 & 0.0016 & 0.0034 & 0.0071 & -0.0002 & 0.0000 & 0.0312 \\
\hline 1978 & 0.0185 & -0.0134 & 0.0085 & -0.0039 & 0.0036 & 0.0010 & -0.0003 & -0.0001 & 0.0138 \\
\hline 1979 & 0.0104 & -0.0051 & 0.0037 & 0.0014 & 0.0037 & 0.0014 & -0.0001 & -0.0001 & 0.0155 \\
\hline 1980 & -0.0009 & -0.0096 & -0.0114 & 0.0010 & 0.0031 & -0.0136 & 0.0000 & -0.0002 & -0.0317 \\
\hline Avrg & 1.0366 & 1.0280 & 1.0134 & 0.9874 & 0.9956 & 1.0100 & 1.0228 & 0.9917 & 0.0235 \\
\hline
\end{tabular}


Table 2. Contributions to the rate of change in $\mathrm{CO2}$ (cont.)

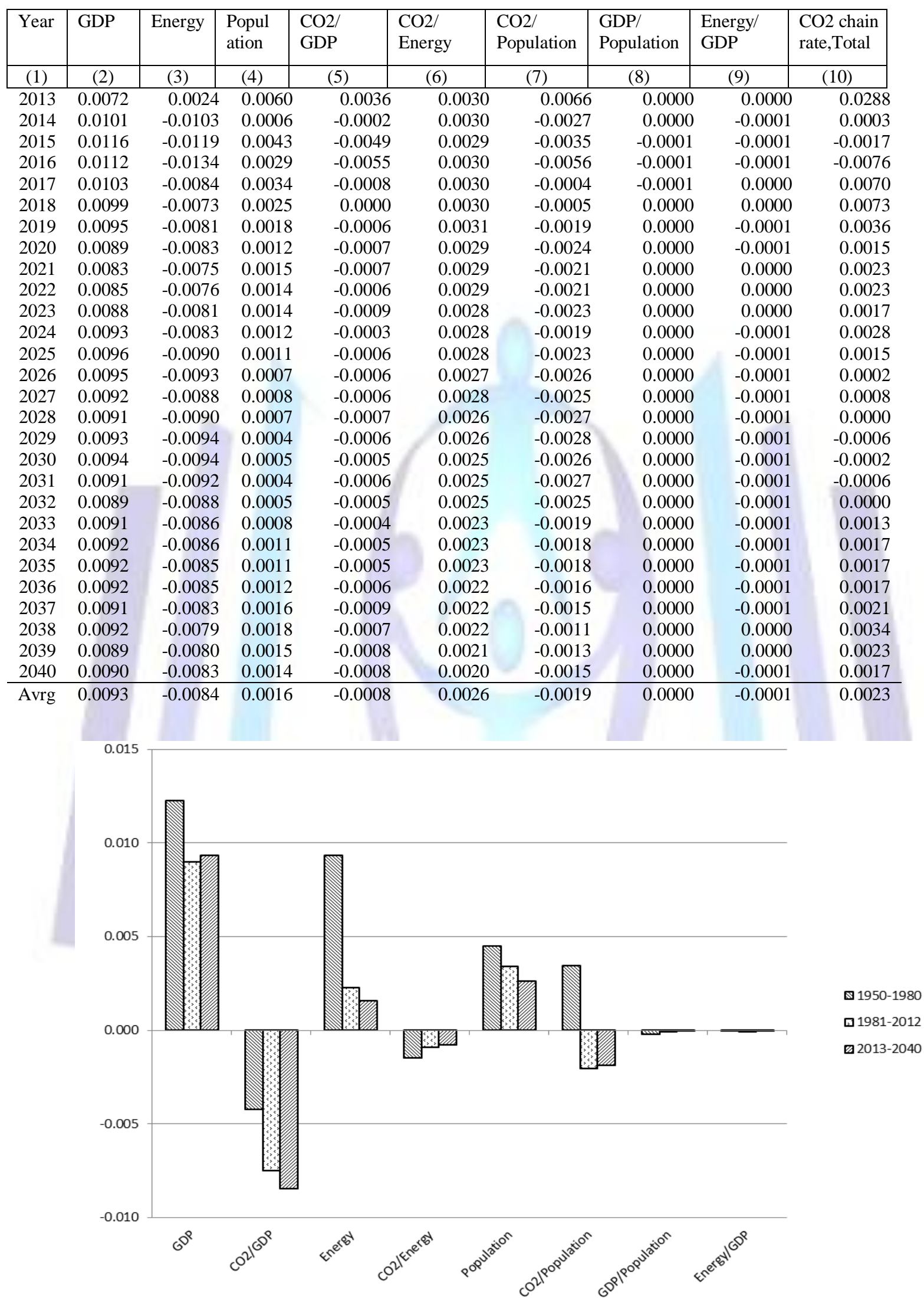

Fig 3: Average contributions to the rate of change in $\mathrm{CO} 2$ emissions 


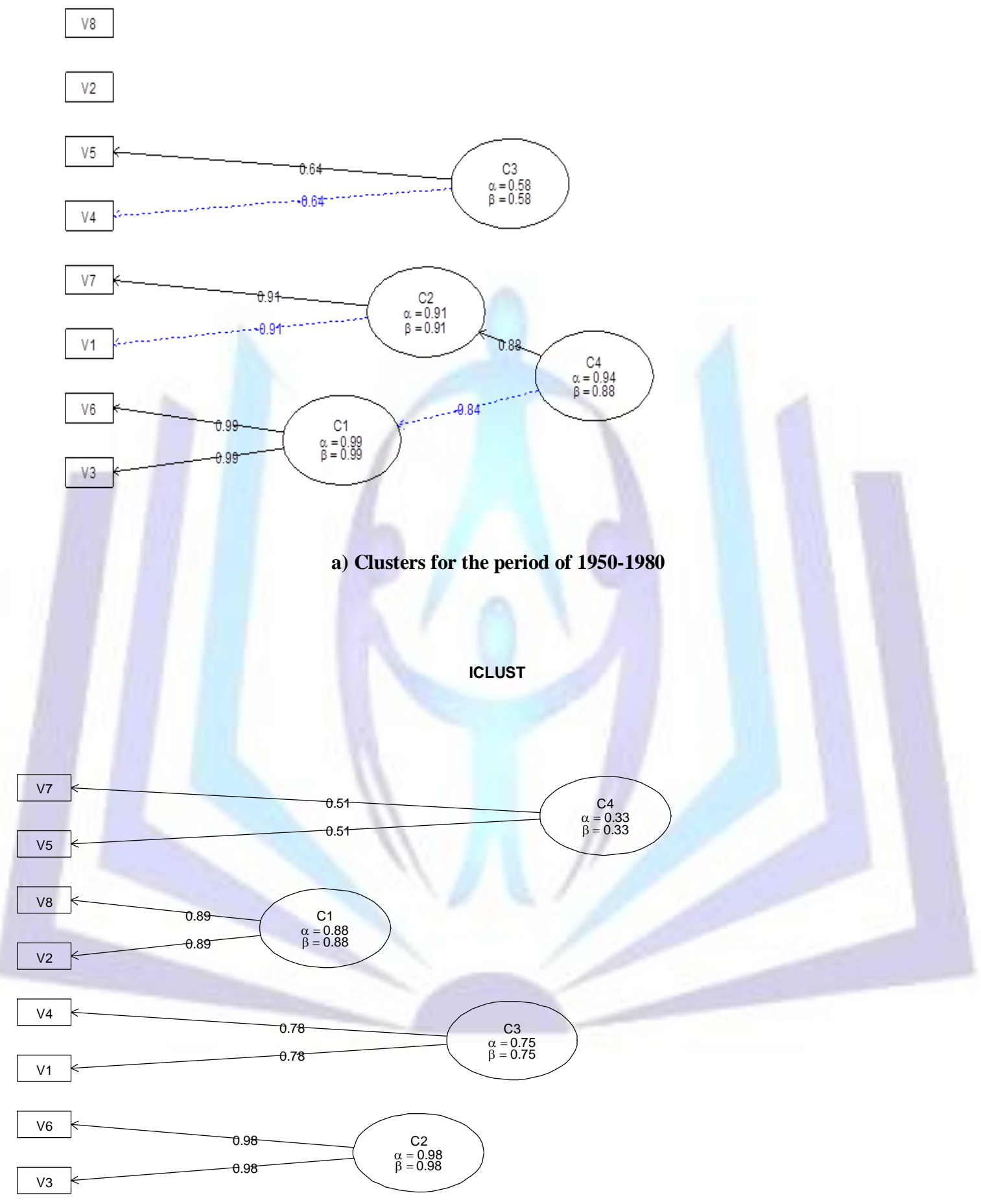

b) Clusters for the period of 1981-2012 
ICLUST

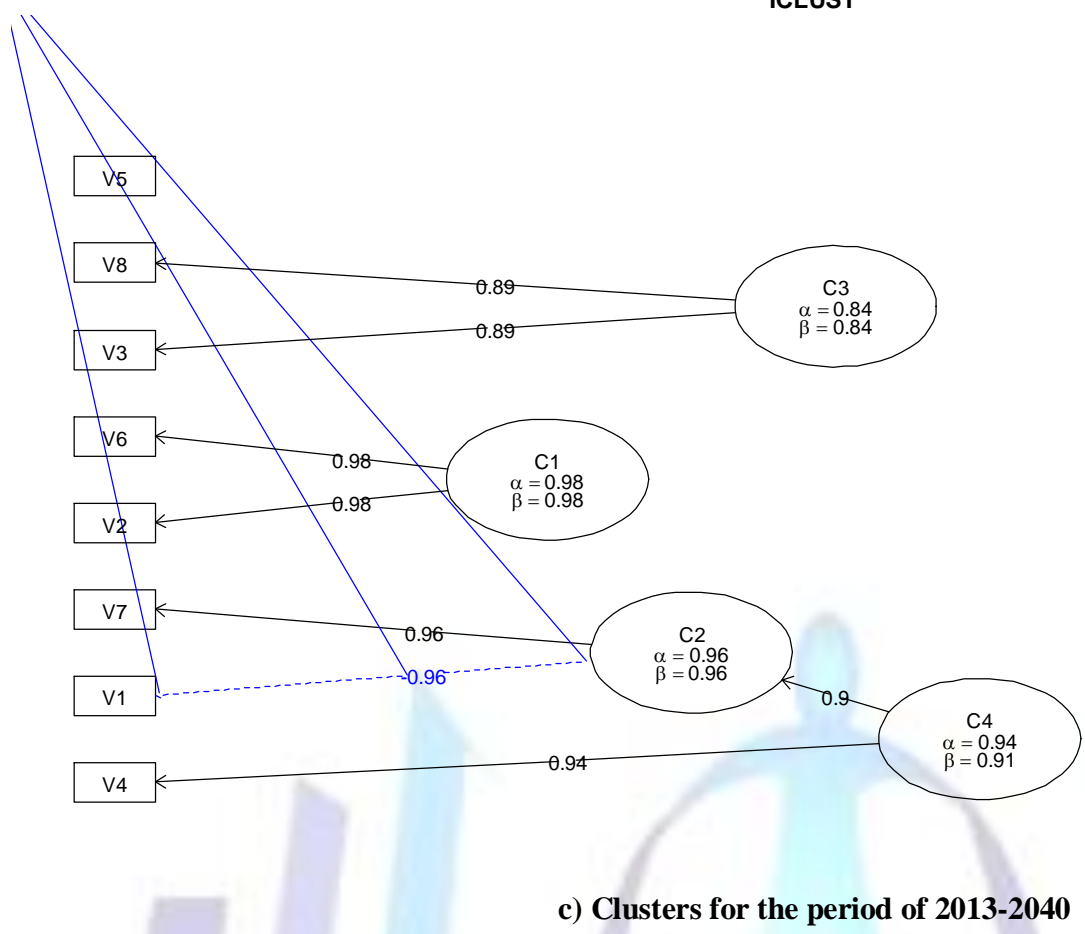

Fig. 4: Clusters of the decomposition variables

V1 - GDP, V2 - Energy, V3 - Population, V4 - CO2/GDP, V5 - CO2/Energy, V6 - CO2/Population, V7 - GDP/Population, V8 Energy/GDP.

Table 3. Clusters of variables by time periods, USA 1950-2040

\begin{tabular}{|c|c|c|c|c|c|c|c|c|c|}
\hline & Variable & GDP & $\begin{array}{l}\mathrm{CO} 2 / \\
\text { GDP }\end{array}$ & Energy & $\begin{array}{l}\mathrm{CO} 2 / \\
\text { Energy }\end{array}$ & $\begin{array}{l}\text { Populat } \\
\text { ion }\end{array}$ & $\begin{array}{l}\mathrm{CO} 2 / \\
\text { Populat } \\
\text { ion }\end{array}$ & $\begin{array}{l}\text { GDP/ } \\
\text { Populat } \\
\text { ion }\end{array}$ & $\begin{array}{c}\text { Energy/ } \\
\text { GDP }\end{array}$ \\
\hline & Abbreviation & V1 & V2 & V3 & V4 & V5 & V6 & V7 & V8 \\
\hline $\begin{array}{l}1951- \\
1980\end{array}$ & $\begin{array}{l}\text { Cluster } 1 \\
\text { Cluster } 2 \\
\text { Cluster } 3 \\
\text { Cluster } 4 \\
\end{array}$ & X & & X & X & X & X & X & \\
\hline $\begin{array}{l}1981- \\
2012\end{array}$ & $\begin{array}{l}\text { Cluster } 1 \\
\text { Cluster } 2 \\
\text { Cluster } 3 \\
\text { Cluster } 4 \\
\end{array}$ & $\mathrm{X}$ & & X & X & & & $X$ & X \\
\hline $\begin{array}{l}2013- \\
2040\end{array}$ & $\begin{array}{l}\text { Cluster } 1 \\
\text { Cluster } 2 \\
\text { Cluster } 3 \\
\text { Cluster } 4 \\
\end{array}$ & $\mathrm{X}$ & X & $\mathrm{X}$ & X & & $\mathrm{X}$ & $\mathrm{X}$ & $\mathrm{X}$ \\
\hline
\end{tabular}

industrial, post-industrial, and information types of the U.S. economy. The chained rates of the CO2 emissions were decomposed into 8 classes each corresponding to GDP, energy consumption, and population, their carbon intensities,GDP per capita, and energy intensity of the GDP. The components of the CO2 rates of change were further subjected to a factor analysis and then to cluster analysis to find the drivers of the CO2 emissions and the ways of their mitigation. We analyzed the dynamics of the clusters' structures corresponding to the main $\mathrm{CO} 2$ drivers as a function of the stage of socioeconomic development and determined the change in the roles of quantitative and qualitative indicators. These findings may be further developed to provide recommendations on optimal environmental policy and economic restructuring. The suggested approach may be used for the analysis of the economies of other countries from the CO2emissions' mitigation perspective.

\section{REFERENCES}

[1] Albert, A. 1993. Regression and Moore - Penrose Pseudoinverse. 1972. Academic Press, New York, 
[2] Bell, D. 1973. The Coming of Post-Industrial Society: A Venture in Social Forecasting, New York: Basic Books.

[3] Beniger, J. 1986. The Control Revolution: Technological and Economic Origins of the Information Society. Cambridge, Mass.: Harvard University Press.

[4] Divisia, F. 1925. L'indice Monetaire et la Theorie de la Monnaie, Revue d'Economic Politique, 39(5):9801020. (In French).

[5] IPCC, 2014: Summary for Policymakers. In: Climate Change 2014: Mitigation of Climate Change. Contribution of Working Group III to the Fifth Assessment Report of the Intergovernmental Panel on Climate Change [Edenhofer, O., R. Pichs-Madruga, Y. Sokona, E. Farahani, S. Kadner, K. Seyboth, A. Adler, I. Baum, S. Brunner, P. $\quad$ Eickemeier, B. Kriemann, J. Savolainen, S. Schlömer, C. von Stechow, T. Zwickel and J.C. Minx (eds.)]. Cambridge University Press, Cambridge, United Kingdom and New York, NY, USA.

[6] Kaya, Y. 1990. Impact of Carbon Dioxide Emission Control on GNP Growth: Interpretation of Proposed Scenarios. Paper presented to the IPCC Energy and Industry Subgroup, Response Strategies Working Group, Paris. (mimeo).

[7] Laspeyres, E. 1871. Die Berechnung einer mittleren Waarenpreissteigerung. Jahrbücher für Nationalökonomie und Statistik, 16, 296-315. (In German).

[8] Maital, S., Vaninsky, A. 2000. Productivity paradoxes and their resolution. Journal of Productivity Analysis, 14(3); $191-207$.

[9] Meerovich V. 1974. Turnover of Financial Funds and Efficiency of Production. (Oborot Sredstv Effektivnost' Proizvodstva), Financy, Moscow. (In Russian.)

[10] Paasche, H. 1874. Über die Preisentwicklung der letzten Jahre nach den Hamburger Börsennotirungen. Jahrbücher für Nationalökonomie und Statistik, 23:168-178.(In German).

[11] R Development Core Team. R: A language and environment for statistical computing. 2011. R Foundation for Statistical Computing,.Vienna, Austria. ISBN 3-900051-07-0, URL http://www.R-project.org/.

[12] Sheremet, A., Dei, G. Shapovalov, V. 1971. The method of the chain substitutions and development of the factorial analysis of the economic indicators (Metod tsepnykh podstanovok i sovershenstvovanie faktornogo analiza ekonomicheskikh pokazatelei). Vestnik Moskovskogo Universiteta, Ser. Ekonomika, 4:62-69. (In Russian).

[13] Thompson, B. 2004. Exploratory and confirmatory factor analysis: Understanding concepts and applications. American Psychological Association, Washington DC.

[14] Vaninsky, A. 1986. Analysis of production efficiency based on the generalized integral method (Analiz effectivnosti proizvodstva na osnove obobschennogo integral'nogo metoda) In Aksenenko, A. (Ed.) Accounting and analysis of production efficiency (Uchet i analiz effectivnosti proizvodstva). 6.1, 212-25. Financy i Statistika, Moscow. (In Russian).

[15] Vaninsky, A. 2013. Economic Factorial Analysis of CO2 Emissions: The Divisia Index with Interconnected Factors Approach. World Academy of Science, Engineering and Technology (WASET). International Journal of Management Science and Engineering, 7(10), 746-751. Available at http://waset.org/publications/17173/.

[16] Vaninsky, A. 2014. Factorial decomposition of CO2 emissions: A generalized Divisia index approach. Energy Economics, vol. 45, 389-400.

[17] Vaninsky, A. 1983. An extension of the integral method of economic analysis to the analysis of interrelated and derivative factors. Avtomatika i Telemekhanika, 8,130-141. Available at http://www.mathnet.ru/php/archive.phtml?wshow=paper\&jrnid=at\&paperid=5200\&option_lang=eng (In Russian). English translation is available in Automation and Remote Control,1984, 44, 8(2), 1074 - 1083.

[18] Vaninsky, A., Meerovich, V. 1978. Problems of the methodology of analysis of the impact of structural change on the indicators of production efficiency, (Voprosy metodologii analiza vliyaniya strukturnykh sdvigov na pokazateli effectivnosti proizvodstva.) Proceedings of the National Scientific Conference "Economic Leverages of the Efficiency of Using Material, Labor, Finance, and Natural Resources", 2, $105 \quad-\quad 107$, Central Economic -Mathematical Institute, Moskva. (In Russian). 